\title{
MIRÍDEOS NEOTROPICAIS. CCCXCIX. ESPÉCIES NOVAS DA AMÉRICA DO SUL (HEMIPTERA)
}

\author{
José C.M. Carvalho ${ }^{1,2}$ \\ Luiz A.A. Costa 1
}

\begin{abstract}
NEOTROPICAL MIRIDAE. CCCXCIX. NEW SPECIES FROM SOUTH AMERICA (HEMIPTERA). Six new species of Hemiptera, Miridae, from South America are described as follows: Chrysodasia pronotata, sp.n.; Ellenia pallida, sp.n.; Horcias niger, sp.n.; Horciasoides ecuatorianus, sp.n.; Neostenotus villensis, sp.n.; Tropidosteptes scutellatus, sp.n. Figures of habitus and male genitalia are included.
\end{abstract}

KEY WORDS. Hemiptera, Miridae, new taxa, South America

Seis espécies novas de Hemiptera, Miridae, são descritas da América do Sul. Foram enviadas pelo Dr. Joseph C. Schaffner, Departamento de Entomologia da Universidade do Texas A \& M e desenhadas por Paulo Roberto Nascimento. As medidas são em milímetros.

\section{Chrysodasia pronotata, sp.n.}

Figs 1-5

Holótipo fêmea. Bolívia: Dept. (Departamento) La Paz, Prov. (Província) Sud Yungas, 4km W Chulumani, 5200', 25-V-1986, J.E. Eger leg., na Coleção do Natural Museum of Natural History, Washington, D.C., Estados Unidos da América. Parátipo: macho, idem, na coleção do primeiro autor.

Diagnose. Reconhecível pela coloração preta do corpo com $2 / 3$ do pronoto amarelo e morfologia da genitália do macho.

Descrição. Corpo: comprimento 5,6; largura 2,8. Cabeça: comprimento 0,4 ; largura 1,2 ; vértice 0,44 . Antena: comprimento segmento I 0,$5 ;$ II 1,6; III 0,8; IV 0,5. Pronoto: comprimento 1,1; largura na base 2,4. Cúneo: comprimento 0,$70 ;$ largura na base 0,60 (holótipo).

Coloração geral do corpo preta com área amarela ou lútea no pronoto; cabeça e olhos pretos; antenas com segmento II na base (exceto extrema base) castanho, preta; rostro castanho. Pronoto preto com 1/4 amarelo ou lúteo. Hemiélitros pretos; membrana com pilosidade muito curta. Lado inferior do corpo castanho, mesosterno branco no meio, peritrema ostiolar branco, abdome

1) Museu Nacional do Rio de Janeiro, Quinta da Boa Vista, 20940-040 Rio de Janeiro, Rio de Janeiro, Brasil.

2) Bolsista do CNPq. 
com faixa branca na região inferior; coxas castanhas, fêmur III castanho na base, negro com anel subapical claro, tíbias III negras.
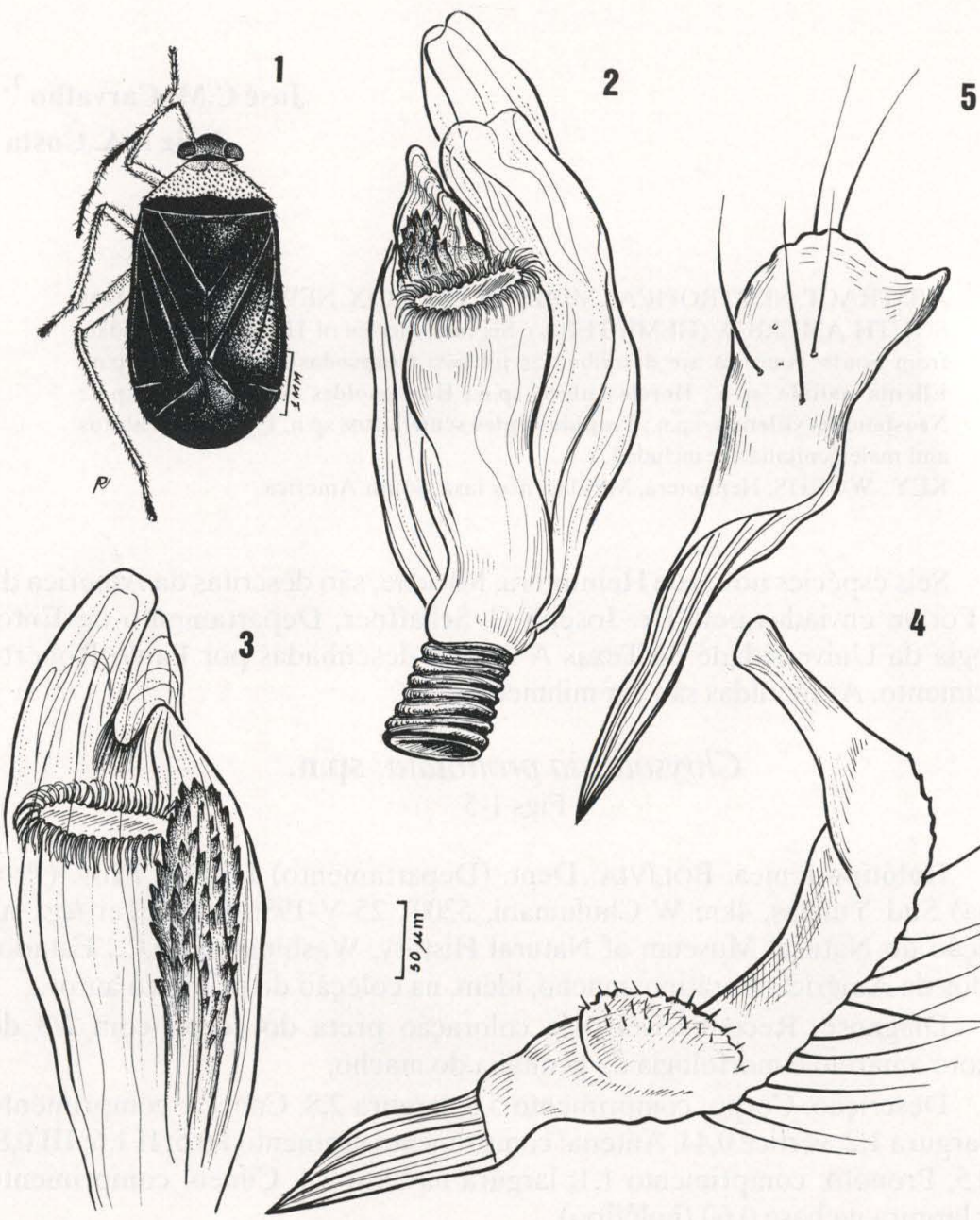

5

4

Figs 1-5. Chrysodasia pronotata, sp.n. (1) Holótipo fêmea; (2-3) vésica; (3) parâmero esquerdo; (4) parâmero direito.

Macho. Um pouco menor que a fêmea, vértice 0,42 .

Genitália. Vésica (Figs 2,3) com um campo lateral de espinhos, longo tubo seminal distal e gonóporo secundário grande e lobos membranosos. Parâmero esquerdo (Fig. 4) com pêlos dorsais longos, lobo basal revestido de espinhos longos e ponta rombuda, curvo. Parâmero direito (Fig. 5) mais largo subapicalmente, com pêlos dorsais e terminado em ponta fina. 
Distribuição geográfica. BolíviA: Departamento de La Paz, Chulumani.

Diferencia-se das outras espécies do gênero pela sua coloração e morfologia da genitália do macho.

O nome específico é alusivo à coloração do pronoto com $2 / 3$ amarelo.

\section{Ellenia pallida, sp.n.}

Figs 6-11

Holótipo fêmea. Bolívia: Dept. (Departamento) La Paz, Prov. (Província) Sud Yungas, Puente Villa, 4300', 19-24-V-1989, J.E. Egerleg., na Coleção do Natural Museum of Natural History, Washington, D.C., Estados Unidos da América. Parátipo: macho, idem, na coleção do primeiro autor.

Diagnose. Reconhecível pela coloração do corpo e pela morfologia da genitália do macho.

Descrição. Corpo: comprimento 3,2; largura 1,4. Cabeça: comprimento 0,2 ; largura 0,7 ; vértice 0,36 . Antena: comprimento segmento I 0,$1 ;$ II 0,$7 ;$ III 0,6 ; IV 0,4. Pronoto: comprimento 0,4; largura na base 1,1. Cúneo: comprimento 0,42 ; largura na base 0,40 (holótipo).

Coloração geral do corpo pálido; cabeça com olhos pretos, vértice claro, restante preto; antena preta; rostro pálido. Pronoto sem colar, calos obsoletos, margem posterior do disco preta, o pronoto é escuro lateralmente, com mesoscuto e escutelo e o próprio pálido. Hemiélitros transparentes, pálidos, com pontos pretos minúsculos e apagados. Corpo dos lados preto e claro inferiormente, mancha negra atingindo o abdome, que é mais claro, peritrema ostiolar parcialmente branco (no ápice), coxas pálidas, fêmures pálidos na base, o III com pontos pretos na porção apical, tíbias pálidas, com pontos negros na base dos espinhos que também são pretos. Características morfológicas como citadas para o gênero, rostro atingindo as coxas medianas.

Macho. Com pontos pretos no meio do disco, escutelo claro, fêmures mais marcados, com duas manchas grandes do lado posterior, vértice 0,20.

Genitália. Pênis (Fig. 7) e vésica (Fig. 8) com gonóporo subterminal, terminando em ponta aguda e um campo de espinhos laterais. Parâmero esquerdo (Fig. 9) com pêlos longos recobrindo o braço menor, o braço maior pontudo. Parâmero direito (Fig. 10) com pêlos longos, rombudo. Teca (Fig. 11) terminada em ponta aguda, porção inferior larga.

Distribuição geográfica. Bolívia: Departamento de La Paz, Puente Villa.

Difere das outras espécies do gênero pela coloração e morfologia da genitália do macho.

$\mathrm{O}$ nome específico é alusivo à coloração. 

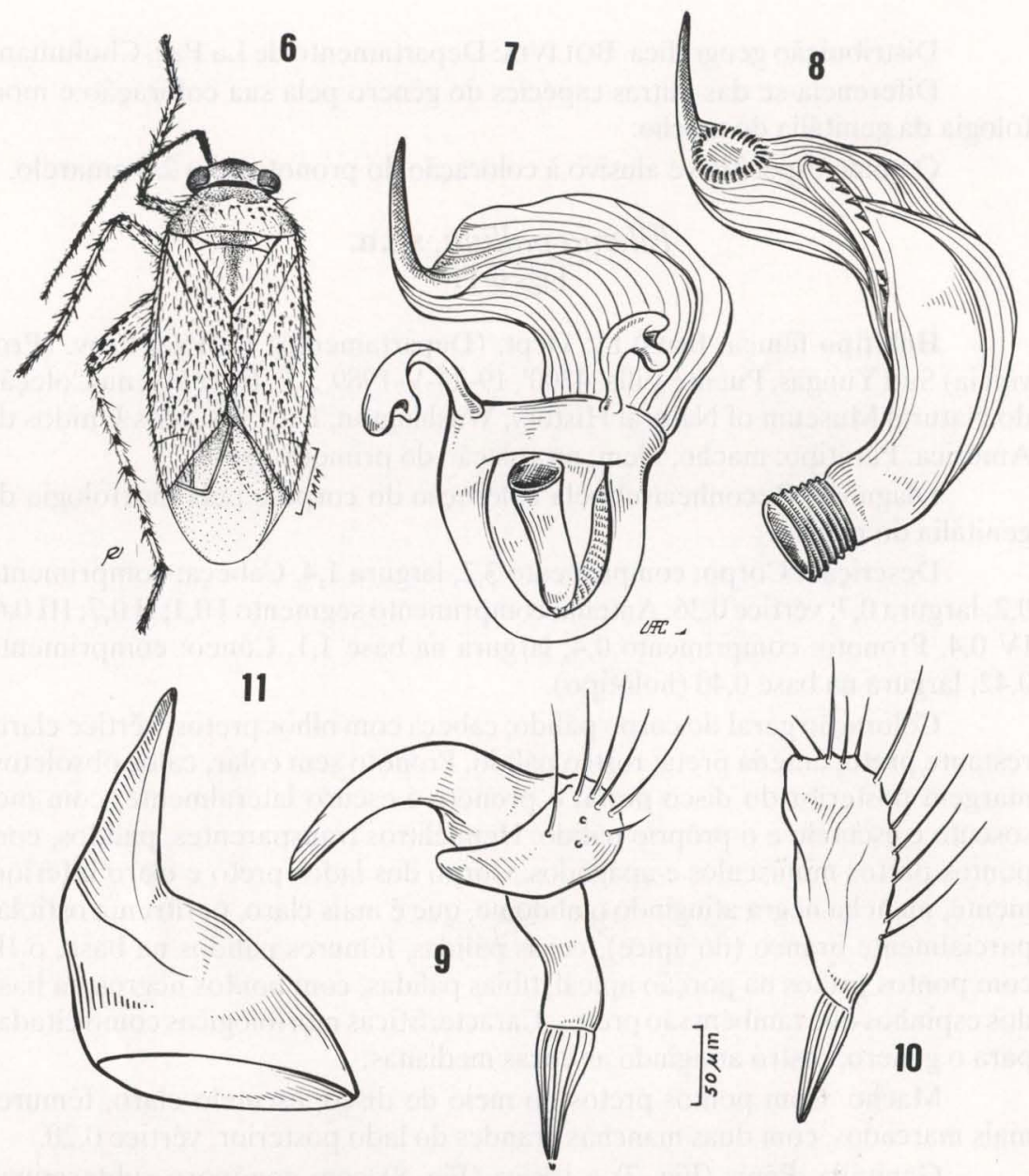

Figs 6-11. Ellenia pallida, sp.n. (6) Holótipo fêmea; (7) pênis; (8) vésica; (9) parâmero esquerdo; (10) parâmero direito; (11) teca.

\section{Horcias niger, sp.n.}

Figs 12-18

Holótipo fêmea. EQUADOR: Pichincha Prov. (Provincia), Tinalandia, $12 \mathrm{~km}$ E Sto. (Santo) Domingo de los Colorados, ca $2500 \mathrm{ft}$., 11-17-V-1986, J.E. Eger leg., na coleção do Natural Museum of Natural History, Washington, D.C., Estados Unidos da América. Parátipo: macho, idem, na coleção do primeiro autor.

Diagnose. Reconhecível pela coloração do corpo e pela morfologia da genitália do macho.

Descrição. Corpo: comprimento 5,2; largura 2,8. Cabeça: comprimento 

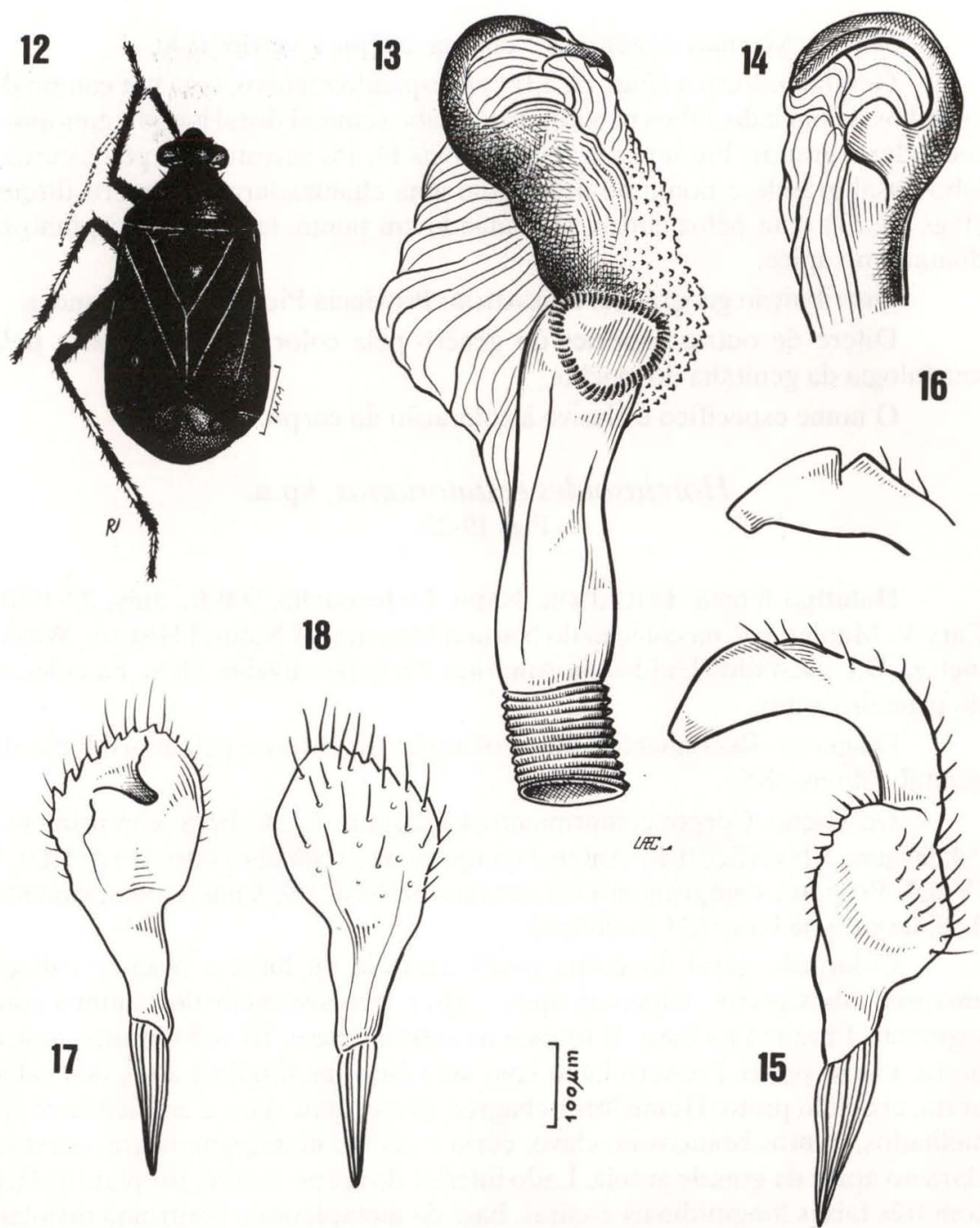

Figs 12-18. Horcias niger, sp.n. (12) Holótipo fêmea; (13-14) vésica; (15-16) parâmero esquerdo; (17-18) parâmero direito.

0,3 ; largura 1,1 ; vértice 0,42 . Antena: comprimento segmento I 0,8 ; II 2,2; III 0,8; IV 1,0. Pronoto: comprimento 1,0; largura na base 2,1. Cúneo: comprimento 0,50 ; largura na base 0,50 (holótipo).

Coloração geral do corpo preta. Lado inferior preto, abdome com três faixas brancas superiores. Fêmures pretos com um ponto branco subapical, fêmur III com dois anéis brancos (mediano e subapical), fêmur II com uma e fêmur I sem a mesma, tarsos com I e II segmentos claros. Características morfológicas como para o gênero. 
Macho. Mesmas dimensões e cor que a fêmea, vértice 0,40.

Genitália. Vésica (Figs 12,13) com espículo recurvo, com um campo de espinhos de um lado, lobos membranosos, tubo seminal distal longo e gonóporo secundário grande. Parâmero esquerdo (Figs 14, 15) revestido de pêlos curtos, lobo basal grande e ponta no ápice com uma chanfradura. Parâmero direito (Figs 16, 17) com pêlos curtos, terminando em ponta, lado dorsal espinhoso, dilatado no ápice.

Distribuição geográfica. EQUADOR: Província Pichincha, Tinalandia.

Difere de outras espécies do gênero pela coloração do corpo e pela morfologia da genitália do macho.

O nome específico é alusivo à coloração do corpo.

\section{Horciasoides ecuatorianus, sp.n.}

Figs 19-23

Holótipo fêmea. EQUADOR: Napo, Ledoconcha, 900 ft., July, 22-1981, Cary V. Manley leg., na coleção do Natural Museum of Natural History, Washington, D.C., Estados Unidos da América. Parátipo: macho, idem, na coleção do primeiro autor.

Diagnose. Reconhecível pela coloração do corpo e pela morfologia da genitália do macho.

Descrição. Corpo: comprimento 4,4; largura 2,1. Cabeça: comprimento 0,4 ; largura 1,1 ; vértice 0,42 . Antena: comprimento segmento I 0,6 ; II 1,5; III 0,7; IV 0,4. Pronoto: comprimento 0,8; largura na base 1,9. Cúneo: comprimento 0,$60 ;$ largura na base 0,34 (holótipo).

Coloração geral do corpo preta, amarela ou lútea e branco; cabeça amarela, olhos pretos, clípeo no ápice, jugo e loro avermelhados; antena com segmento I branco na base, II branco na extrema base, III todo branco, ápice preto; rostro preto. Pronoto lúteo com uma faixa longitudinal atrás dos calos preta, escutelo preto. Hemiélitros chagrén, preto, com clavo e endocório avermelhados, pontos brancos no clavo, cório e cúneo; membrana negra, nervura clara no ápice da grande aréola. Lado inferior do corpo escuro, propleura clara com três faixas longitudinais escuras, base da metapleura e peritrema ostiolar, duas linhas no abdome superiormente (a de baixo mais pronunciada); coxas negras, fêmures negros na base, com anel branco submediano e ápice com manchas negras; tíbias negras, com dois anéis brancos (mediano e subapical), tarsos com segmento I claro.

Macho. Com as mesmas dimensões e coloração da fêmea, com cúneo claro e avermelhado na base, vértice 0,40 .

Genitália. Vésica (Fig. 20) com duas pontas agudas. Parâmero esquerdo (Fig. 21) com lobo basal grande, revestido por espinhos curtos, curvo, com pêlos superficiais, terminado em ponta recurva, porção terminal afilada. Parâmero direito (Fig. 22) revestido por pêlos longos, dilatado apicalmente. Teca (Fig. 23) com porção afilada, dilatada ventralmente. 


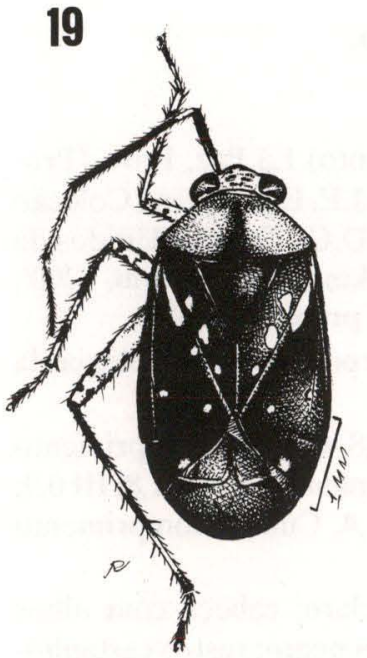

20
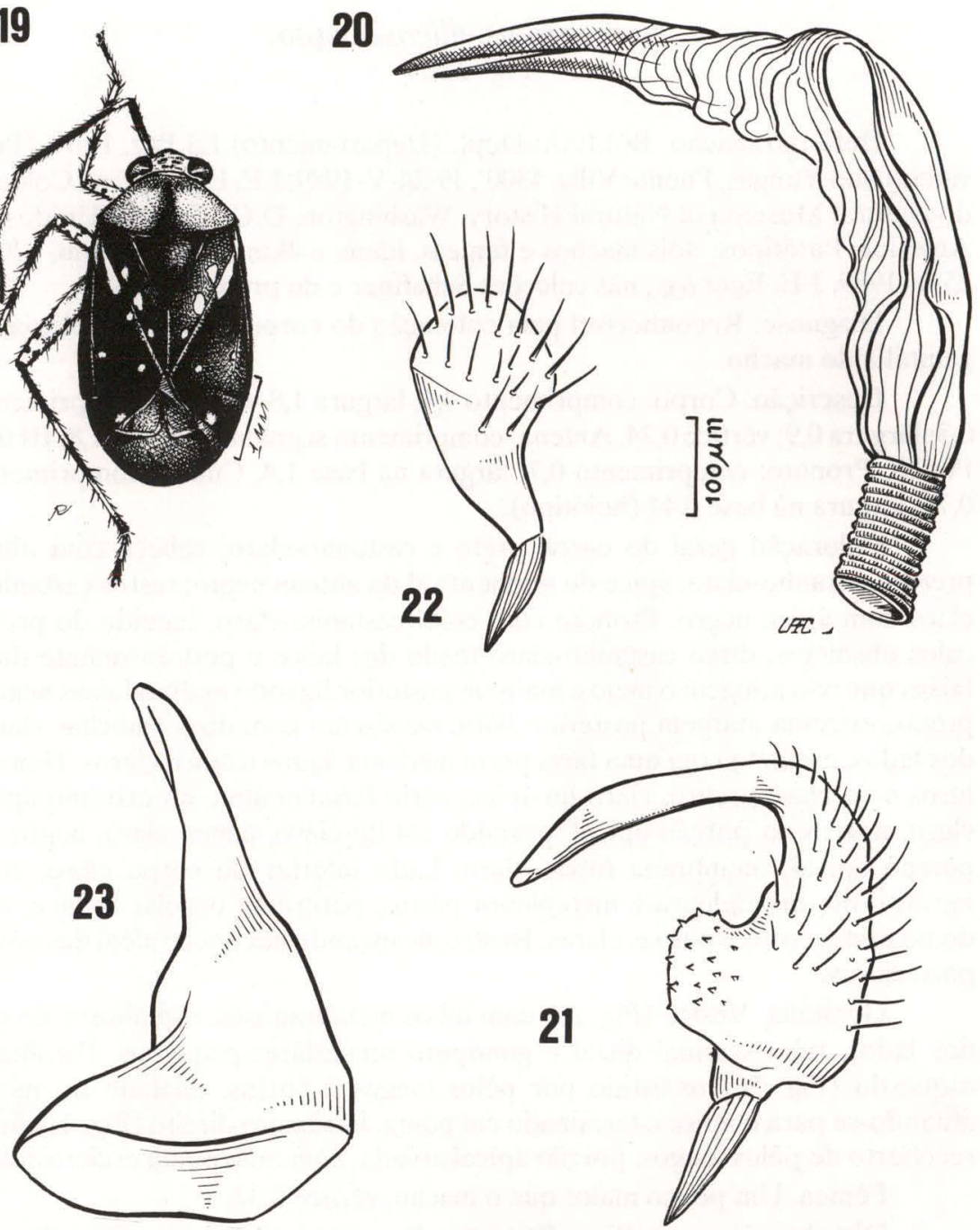

Figs 19-23. Horciasoides ecuatorianus, sp.n. (19) Holótipo fêmea; (20) vésica; (21) parâmero esquerdo; (22) parâmero direito; (23) teca.

Distribuição geográfica. EQUADOR: Napo, Ledoconcha.

Difere das demais espécies do gênero pela coloração do corpo e pela morfologia da genitália do macho.

O nome específico é alusivo ao país onde a espécie tipo foi colecionada. 


\section{Neostenotus villensis, sp.n.}

Figs 24-27

Holótipo macho. Bolívia: Dept. (Departamento) La Paz, Prov. (Província) Sud Yungas, Puente Villa, 4300', 19-24-V-1989, J.E. Eger leg., na Coleção do Natural Museum of Natural History, Washington, D.C., Estados Unidos da América. Parátipos: dois machos e fêmeas, idem, e 4km W Chulumani, 5200', 25-V-1989, J.E. Eger leg., nas coleções Schaffner e do primeiro autor.

Diagnose. Reconhecível pela coloração do corpo e pela morfologia da genitália do macho.

Descrição. Corpo: comprimento 4,4; largura 1,8. Cabeça: comprimento 0,3 ; largura 0,9 ; vértice 0,24 . Antena: comprimento segmento I 0,7 ; II 1,8; III 0,9; IV 0,8. Pronoto: comprimento 0,7; largura na base 1,4. Cúneo: comprimento 0,70 ; largura na base 0,44 (holótipo).

Coloração geral do corpo preto e castanho-claro; cabeça com olhos pretos, castanho-clara, ápice do segmento II da antena negro; rostro castanhoclaro com ápice negro. Pronoto com colar castanho-claro, seguido do preto, calos obsoletos, disco castanho-claro tendo dos lados e posteriormente duas faixas que não atingem o meio e margem posterior ligando as duas faixas negras pretas, extrema margem posterior clara, mesoscuto com duas manchas claras dos lados, escutelo com uma faixa preta mediana, lados e ápice claros. Hemiélitros com clavo escuro, claro no ápice, cório basalmente e no extremo ápice claro, negros na porção apical, pegando $1 / 4$ do clavo, cúneo claro, negro na porção apical; membrana fusca, clara. Lado inferior do corpo claro, com mesosterno, mesopleura e metapleura pretos, peritrema ostiolar branco, abdome preto, coxas e pernas claras. Rostro alcançando um pouco além das coxas posteriores.

Genitália. Vésica (Fig. 25) com lobos membranosos, espinhosos de um dos lados, tubo seminal distal e gonóporo secundário pequenos. Parâmero esquerdo (Fig. 26) revestido por pêlos longos e curtos, dilatado no meio, afilando-se para o ápice e terminado em ponta. Parâmero direito (Fig. 27) fino, recoberto de pêlos longos, porção apical afilada, com uma ponta esclerosada.

Fêmea. Um pouco maior que o macho, vértice 0,32 .

Distribuição geográfica. BolíviA: Departamento de La Paz, Puente Villa e Chulumani.

Difere das outras espécies do gênero pela coloração do corpo e pela morfologia da genitália do macho.

O nome específico é alusivo à Villa, onde a espécie foi colecionada.

\section{Tropidosteptes scutellatus, sp.n.}

Figs 28-31

Holótipo macho. Venezuela: Lara, 1 km S Cubrio, 1600m, Dec. (December) 27-1985, P. Kovarik \& R. Jones leg., na Coleção do Natural Museum 

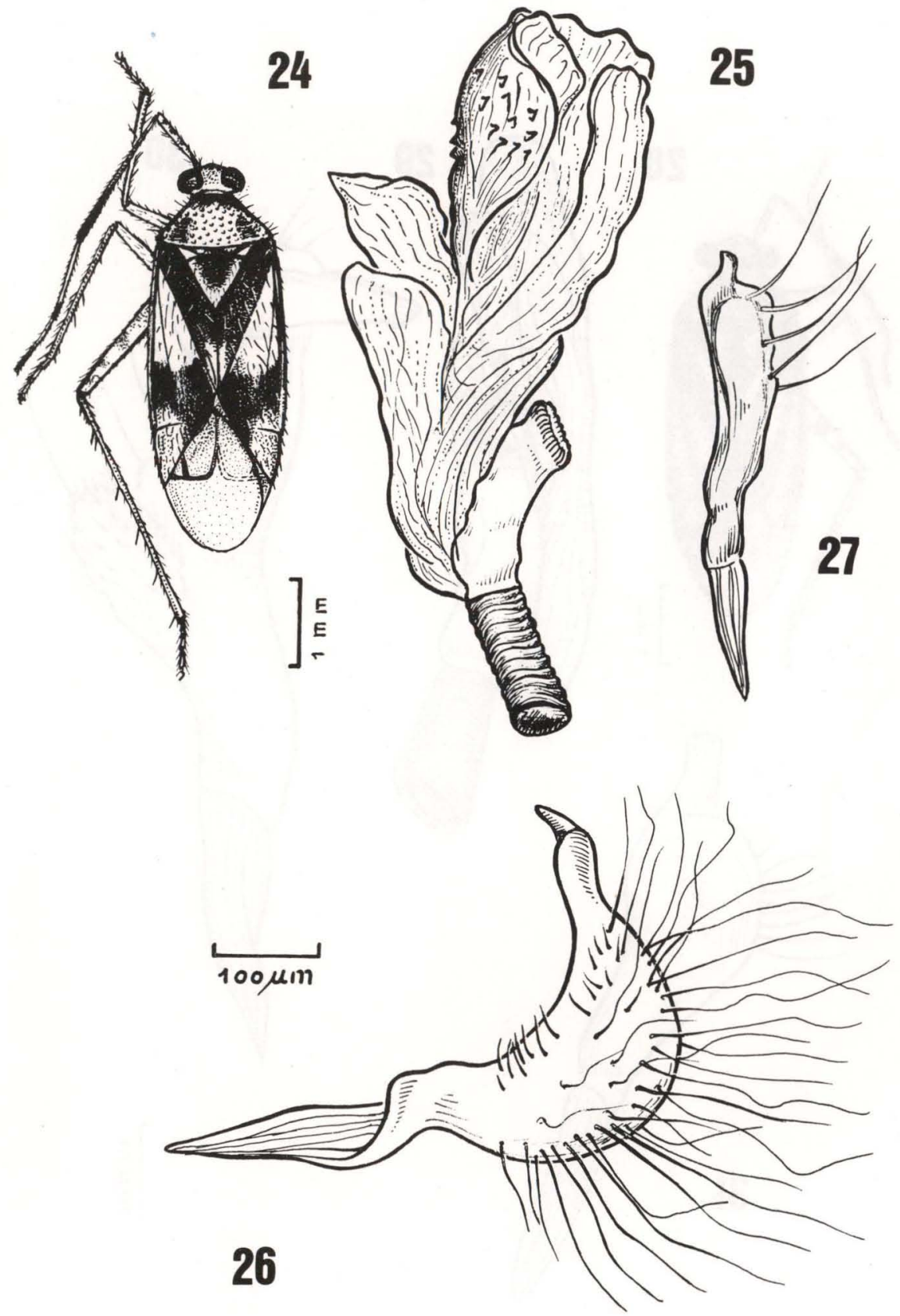

Figs 24-27. Neostenotus villensis, sp.n. (24) Holótipo macho; (25) vésica; (26) parâmero esquerdo; (27) parâmero direito. 


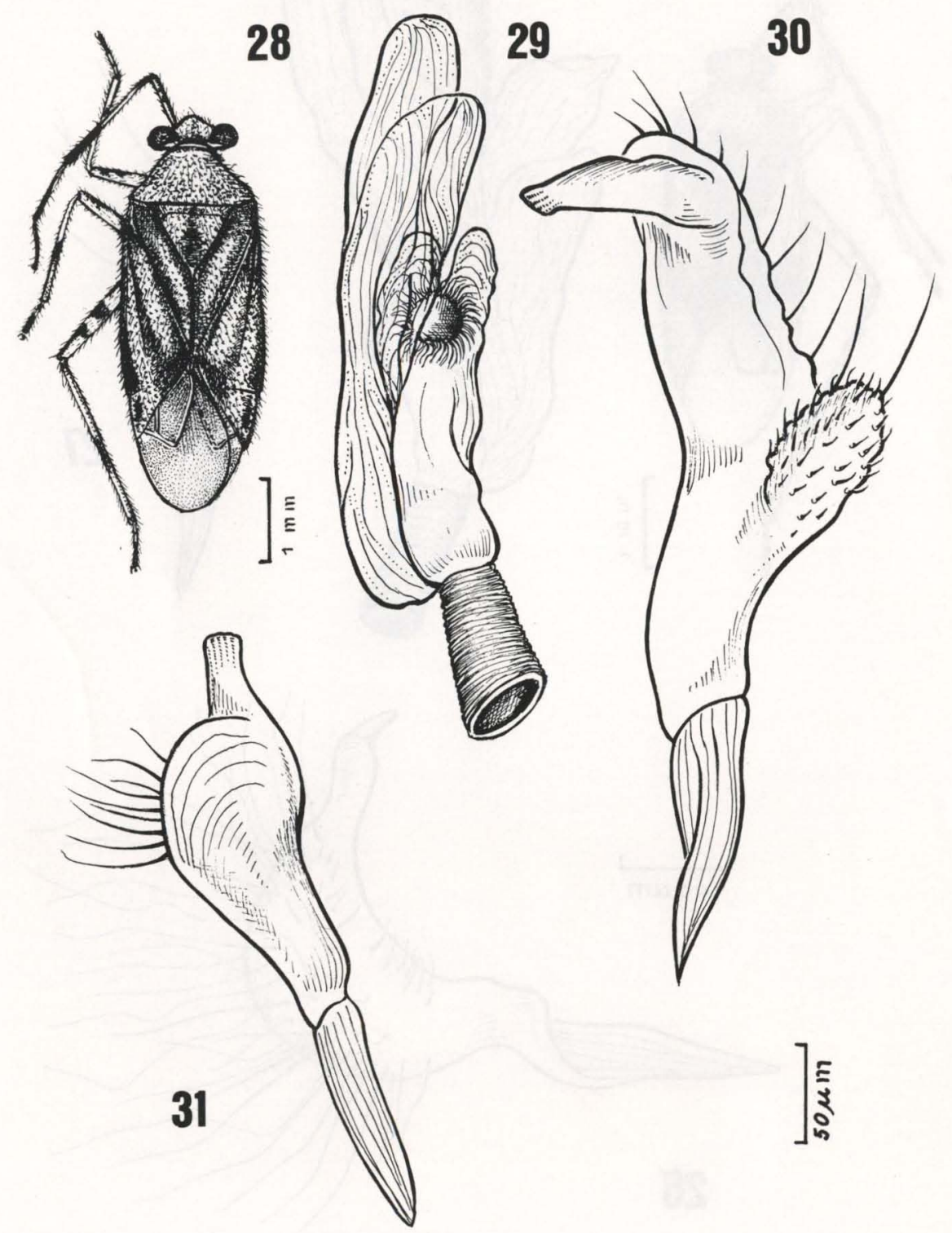

Figs 28-31. Tropidosteptes scutellatus, sp.n. (28) Holótipo macho; (29) vésica; (30) parâmero esquerdo; (31) parâmero direito. 
of Natural History, Washington, D.C., Estados Unidos da América. Parátipo. Macho, idem, na coleção do primeiro autor.

Diagnose. Reconhecível pela coloração do escutelo e morfologia da genitália do macho.

Descrição. Corpo: comprimento 5,2; largura 1,6. Cabeça: comprimento 0,3 ; largura 1,1; vértice 0,30 . Antena: comprimento segmento I 0,6; II 1,4; III 0,8; IV 0,4. Pronoto: comprimento 0,8; largura na base 1,5. Cúneo: comprimento 0,60 ; largura na base 0,44 (holótipo).

Coloração geral do corpo parda a castanha; segmento I da antena negro, preto para o ápice, segmento II pálido na extrema base, seguido por anel negro, castanho a seguir e preto no ápice, segmento III castanho na base, negro no ápice, restante negro; rostro castanho, negro no ápice. Pronoto da mesma cor dos hemiélitros, escutelo claro, com uma faixa longitudinal mediana escura. Hemiélitro com clavo negro internamente e na sutura, restante e ápice mais claro, cório no ápice, cúneo idem e na margem interna brancos; membrana fusca, nervuras brancas. Lados do corpo com uma faixa negra percorrendo superiormente, coxas, mesosterno no meio e fêmures para a base brancos, ápice e tíbias negros, fêmures III com dois anéis (subapical e apical separados por uma mancha branca).

Genitália. Vésica (Fig. 29) com lobos membranosos, tubo seminal longo, abertura do gonóporo secundário média. Parâmero esquerdo (Fig. 30) com ápice recurvado, lobo basal grande, provido de pêlos médios e compridos. Parâmero direito (Fig. 31) dilatado próximo ao ápice, terminado em ponta rombuda, com dentículos terminais.

Fêmea. Desconhecida.

Distribuição geográfica. VENEZUELA: Lara, Cubrio.

Difere das outras espécies do gênero pela coloração e pela morfologia da genitália do macho.

O nome específico é alusivo à coloração do escutelo.

\section{REFERÊNCIAS BIBLIOGRÁFICAS}

CARVALHO, J.C.M. 1976. Mirídeos Neotropicais, CC: Revisão do gênero Horcias Distant, com descrições de espécies novas (Hemiptera). Rev. Brasil. Biol. 36 (2): 429-472.

1986. Mirídeos Neotropicais, CCLXVI: Gênero Chrysodasia Reter, com descrições de novas espécies (Hemiptera). Rev. Brasil. Biol. 46 (1): 217-229.

1986. Mirídeos Neotropicais, CCLXX: Espécies regionais do gênero Tropidosteptes Uhler (Hemiptera). Rev. Brasil. Biol. 46 (2): 401-413.

CARVALHO, J.C.M. \& A.V. FONTES. 1972. Mirídeos Neotropicais, CXLI: Gênero Alda Reuter, com descrição de novas espécies (Hemiptera). Rev. Brasil. Biol. 32 (1): 85-98. 